THAIS RIBEIRO SEMPREBOM

\title{
GLUTAMINA E METABOLISMO ANTIOXIDANTE DURANTE A ORGANOGÊNESE ADVENTÍCIA EM FOLHAS DE Ananas comosus
}

São Paulo

2008 
THAIS RIBEIRO SEMPREBOM

\section{GLUTAMINA E METABOLISMO ANTIOXIDANTE DURANTE A ORGANOGÊNESE ADVENTÍCIA EM FOLHAS DE Ananas comosus}

Dissertação apresentada ao Instituto de Biociências da Universidade de São Paulo, para a obtenção do Título de Mestre em Ciências, na Área de Botânica, Fisiologia Vegetal.

Orientador(a): Dra. Helenice Mercier

São Paulo

2008 
Semprebom, Thais Ribeiro

Glutamina e metabolismo antioxidante durante a organogênese adventícia em folhas de Ananas comosus

Total de 76 páginas

Dissertação (Mestrado) - Instituto de Biociências da Universidade de São Paulo.

Departamento de Botânica.

1. Bromeliaceae 2. Organogênese 3.

Glutamina 4. Metabolismo antioxidante

I. Universidade de São Paulo. Instituto de

Biociências. Departamento de Botânica.

Apoio de fomento: Fundação de Amparo a Pesquisa do Estado de São Paulo (FAPESP)

Comissão Julgadora:

$\operatorname{Prof}(a) . \operatorname{Dr}(a)$.

$\operatorname{Prof}(\mathrm{a}) . \operatorname{Dr}(\mathrm{a})$.

Prof(a). Dr.(a).

Orientador(a) 


\section{ÍNDICE}

Pág.

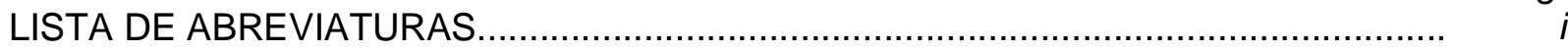

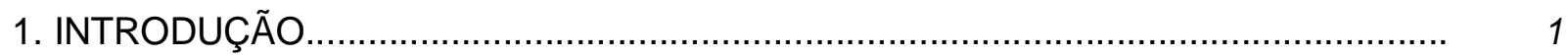

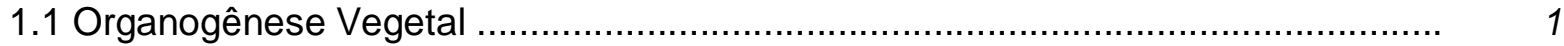

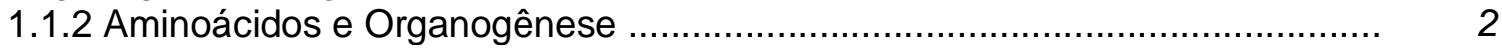

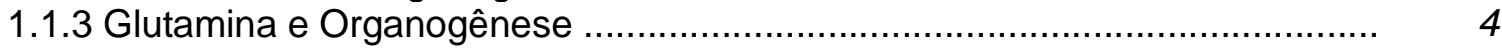

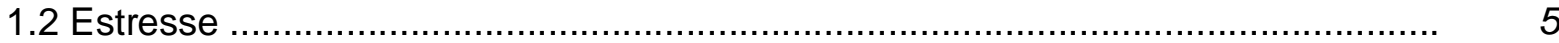

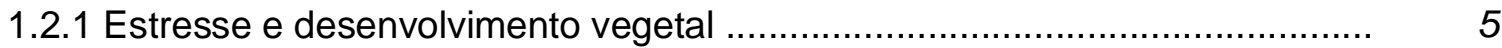

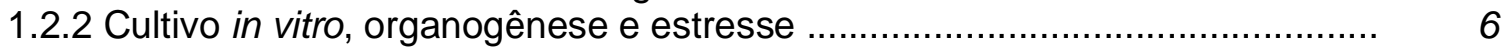

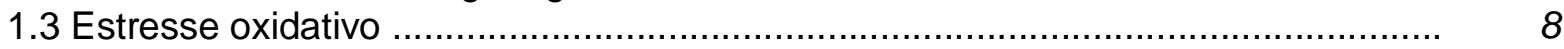

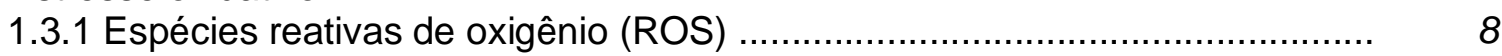

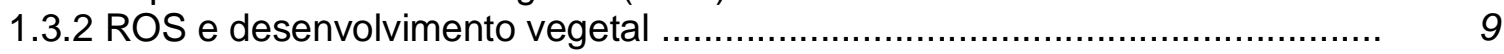

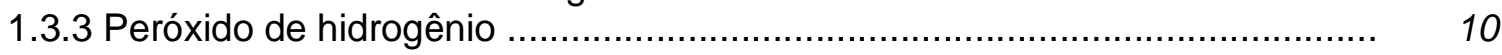

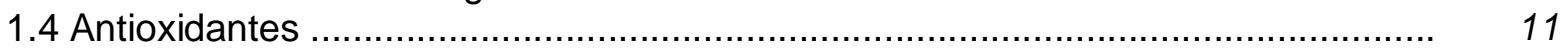

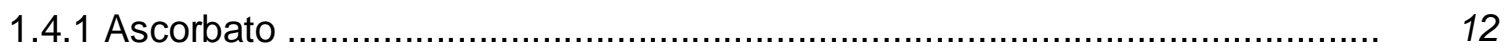

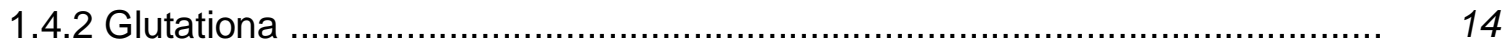

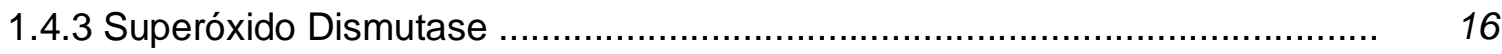

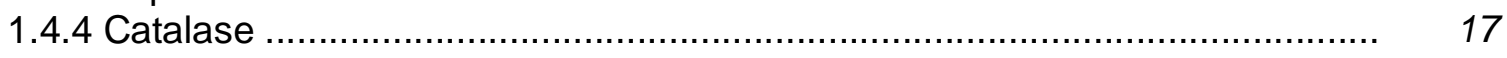

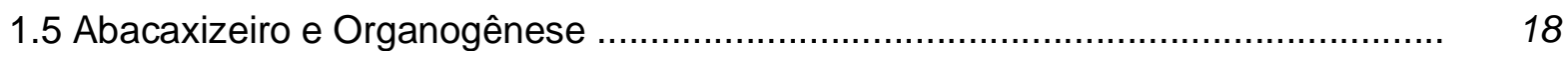

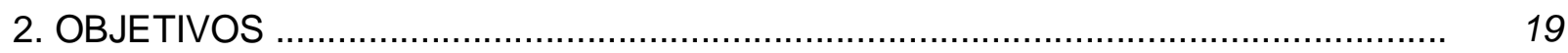

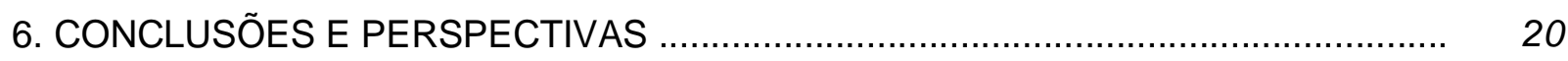

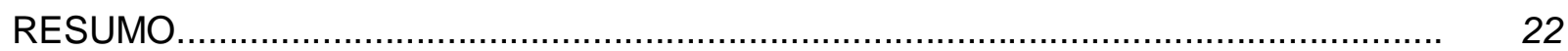

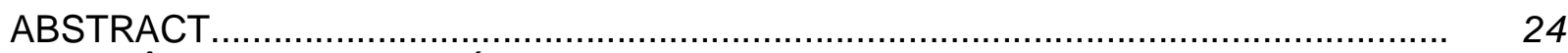

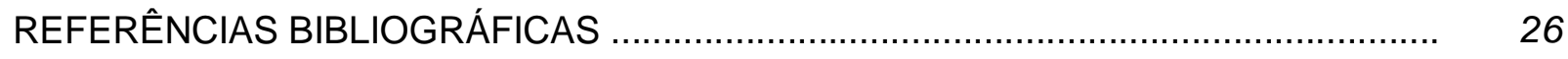




\section{LISTA DE FIGURAS}

$\begin{array}{ll}\text { V-ECS } & \text { Y-glutamilcisteína sintetase } \\ \text { AAP } & \text { 4-aminoantipirina } \\ \text { ANA } & \text { ácido naftalenoacético } \\ \text { APX } & \text { ascorbato peroxidase } \\ \text { ASC } & \text { ascorbato, ascorbato reduzido } \\ \text { BA } & \text { benziladenina } \\ \text { CAT } & \text { catalase } \\ \text { DCHBS } & \text { ácido 3,5-dicloro-2-hidroxibenzesulfônico } \\ \text { DHA } & \text { dehidroascorbato, ascorbato oxidado } \\ \text { DHAR } & \text { dehidroascorbato redutase } \\ \text { DTT } & \text { ditiotreitol } \\ \text { GAL } & \text { L-galactono- Y-lactona } \\ \text { GR } & \text { glutationa redutase } \\ \text { GSH } & \text { glutationa, glutationa reduzida } \\ \text { GSH-S } & \text { glutationa sintetase } \\ \text { GSSG } & \text { glutationa dissulfídeo, glutationa oxidada } \\ \text { MDHA } & \text { monodehidroascorbato } \\ \text { MDHAR } & \text { Monodehidroascorbato redutase } \\ \text { PVPP } & \text { polivinilpirrolidona } \\ \text { POX } & \text { peroxidase } \\ \text { ROS } & \text { espécies reativas de oxigênio } \\ \text { SIM } & \text { meio de indução de eixos caulinares } \\ \text { SIMGln } & \text { meio de indução de eixos caulinares acrescido de glutamina } \\ \text { SOD } & \text { superóxido dismutase } \\ & \end{array}$




\section{INTRODUÇÃO}

\subsection{Organogênese Vegetal}

A organogênese é definida como o aparecimento de um novo órgão (raiz, folha ou eixo caulinar), inicialmente como uma protuberância, em um local onde havia somente uma estrutura parental (Green, 1980). Segundo Sugiyama (1999), a organogênese in vitro consiste de vários aspectos, tais como a percepção de fitormônios, a aquisição de competência organogenética, a re-entrada das células quiescentes no ciclo celular e a organização da divisão celular para formar primórdios e meristemas de órgãos específicos.

Na chamada organogênese adventícia, novos órgãos se originam a partir de tecidos já diferenciados, normalmente folhas, caules ou raízes (Kerstetter \& Hake, 1997). Segundo esses autores, a totipotência demonstrada pela capacidade de células vegetais diferenciadas organizarem meristemas caulinares adventícios sugere que, virtualmente, qualquer célula viva ou grupos de células na planta tem potencial para formar um meristema, dadas as condições e os sinais apropriados.

De maneira geral, podem ser reconhecidas três fases na organogênese, de acordo com o tempo requerido para haver um controle hormonal equilibrado sobre o processo (Christianson \& Warnick, 1985). São elas: a) aquisição de competência - as células do tecido cultivado tornam-se capazes de responder aos estímulos indutores da organogênese; b) indução - as células competentes tornam-se determinadas à formação de um órgão específico, sob a influência da composição hormonal do meio de cultura; c) diferenciação - as células do tecido se diferenciam e se desenvolvem em raízes ou eixos caulinares, independentemente dos reguladores de crescimento do meio de cultura.

No que se refere aos estudos da organogênese vegetal in vitro, os 
trabalhos investigam uma série de fatores envolvidos no controle desse processo, dentre os quais: balanço hormonal (Christianson \& Warnick, 1985; Tang \& Guo, 2001; Rao et al., 2005; Valdés et al., 2001) e fontes de nitrogênio (Shetty et al., 1992; Milazzo et al., 1998; Kamada \& Harada, 1979; Tsai \& Saunders, 1999).

\subsubsection{Aminoácidos e Organogênese}

O nitrogênio é constituinte de um grande número de importantes compostos encontrados nas células vivas, como aminoácidos, proteínas e ácidos nucléicos, entre outros (Lea, 1993). Compostos nitrogenados são considerados limitantes ao crescimento e desenvolvimento vegetal, além de estarem relacionados com a sinalização de eventos fisiológicos, como a embriogênese somática (Kamada \& Harada, 1984) e a organogênese (Kamada \& Harada, 1979; Tang \& Guo, 2001).

$\mathrm{Na}$ cultura de tecidos os meios nutritivos comumente utilizados possuem diferentes quantidades de nitrogênio, em grande parte fornecido inorganicamente por alguma combinação de nitrato e amônio (Tsai \& Saunders, 1999). Compostos de nitrogênio orgânico, como os aminoácidos, são utilizados por meio de vias metabólicas primárias em vários aspectos do ciclo de vida das plantas, controlando direta ou indiretamente o crescimento e desenvolvimento vegetal (Joy IV et al., 1994; Coruzzi \& Last, 2000).

O nitrogênio originado de aminoácidos é assimilado rapidamente em esqueletos carbônicos durante o metabolismo e síntese de proteínas, quando comparado a outras fontes inorgânicas de nitrogênio (Lea, 1993). Ao suplementar o meio de cultura com misturas de aminoácidos ou preparações de proteínas hidrolisadas, freqüentemente intensifica-se o crescimento vegetal, embora certos aminoácidos possam inibi-lo (Gamborg, 1970). 
Joy IV et al. (1994) sugeriram que o metabolismo primário de nitrogênio foi estimulado durante os primeiros estágios da organogênese de Pinus radiata em comparação a tecidos não formadores de órgão, que se tornaram senescentes. De acordo com Kamada \& Harada (1979), o nitrogênio na forma de aminoácidos, no meio de cultura, foi essencial à indução da organogênese de Torenia fournieri. Milazzo et al. (1998) verificaram que a suplementação do meio de cultura com prolina estimulou a organogênese de gemas caulinares induzidas por benziladenina (BA) em cotilédones de melão (Cucumis melo). Segundo esses autores, a prolina teria estimulado a organogênese por meio da ligação desse aminoácido à via das pentoses fosfato, que regularia a biossíntese de citocininas e auxinas endógenas.

Aminoácidos podem, ainda, estar envolvidos na maneira como as plantas absorvem e assimilam os nutrientes, em particular o nitrato e o amônio. Dluzniewska et al. (2006) observaram que, ao adicionar glutamina à solução nutritiva empregada no cultivo de álamo, houve um aumento na concentração de diferentes compostos nitrogenados nas raízes, correlacionando negativamente com a capacidade de absorção de nitrato, além de ter alterado a distribuição da assimilação de nitrogênio entre raiz-parte aérea em favor das folhas e de ter alterado a ciclagem interna de nitrogênio da planta.

Em bromélias cultivadas in vitro, a substituição das fontes nitrogenadas originais do meio de cultura $\left(\left(\mathrm{NH}_{4}\right)_{2} \mathrm{SO}_{4}\right.$ e $\left.\mathrm{Ca}\left(\mathrm{NO}_{3}\right)_{2}\right)$ por glutamina ou nitrato de amônio resultou em melhor crescimento do eixo caulinar, expressado pelo aumento da massa seca (Mercier \& Kerbauy, 1998). As fontes nitrogenadas exerceram uma forte influência sobre o balanço entre auxinas/citocininas, cujos conteúdos endógenos variaram acentuadamente dependendo da fonte de nitrogênio utilizada (Mercier et al., 1997). 


\subsubsection{Glutamina e Organogênese}

A glutamina é uma fonte de nitrogênio orgânico comumente utilizada em meios de cultura de tecido de plantas superiores (Franklin \& Dixon, 1994), sendo que vários pesquisadores demonstraram o envolvimento benéfico da suplementação do meio de cultura com esse aminoácido. Entretanto, poucas são as hipóteses acerca do modo de ação desse aminoácido.

Altas concentrações de glutamina no meio de cultura aumentaram a proliferação de tecidos embriogênicos de Cryptomeria japonica, sugerindo-se que o tratamento com glutamina teria aumentado a síntese de macromoléculas ou metabólitos essenciais à manutenção da competência das células à embriogênese (Ogita et al., 2001). O conteúdo endógeno de glutamina aumentou rapidamente durante os primeiros estágios de iniciação de gemas adventícias em segmentos caulinares de Torenia, sugerindo que o acúmulo desse aminoácido nas células deva ser um dos fatores necessários para a iniciação de gemas adventícias (Tanimoto \& Harada, 1989).

Hamasaki et al. (2005) observaram que o período de indução da organogênese de bases foliares de abacaxizeiro ocorreu entre o primeiro e o sétimo dias de cultivo in vitro no meio de cultura suplementado com $8 \mathrm{mM}$ de glutamina. Nesse período, as células competentes da base foliar responderam aos sinais gerados pela adição do aminoácido no meio de cultura. Ao se quantificar o conteúdo endógeno de glutamina nos explantes foliares de abacaxizeiro, observou-se que houve uma drástica redução na quantidade desse aminoácido nas primeiras horas de cultivo in vitro (Kitakawa, 2004). Entretanto, quando o meio de cultura continha glutamina, o reaparecimento da glutamina endógena se fez mais rapidamente do que em explantes cultivados sem o aminoácido. Imaginou-se que nesse período inicial do cultivo in vitro, quando se acredita que o estresse deva ser bastante elevado, a glutamina endógena poderia ser um marcador do tempo em que o explante está submetido a um alto grau de 
estresse. Assim que a glutamina reaparecesse endogenamente, marcaria o final do período crítico do estresse.

\subsection{Estresse}

A investigação das bases fisiológicas e moleculares das alterações fenotípicas, que possibilitaram que as plantas se adaptassem à grande variedade de ambientes, explora uma rica gama de informações (Weigel \& Dean, 2002) e muito se tem estudado a respeito dos estresses aos quais as plantas podem estar sujeitas.

Para Larcher (1980), estresses são mudanças na fisiologia quando da exposição das plantas a condições desfavoráveis, que não necessariamente representem ameaça à vida, mas induzirão uma resposta defensiva ou adaptativa ao estímulo. Segundo Nilsen \& Orcutt (1996), fisiologicamente, estresse é a condição causada por fatores que tendem a alterar um equilíbrio.

O estresse desencadeia uma série de respostas nas plantas, desde expressão gênica e metabolismo celular alterados até mudanças nas taxas de crescimento (Bray et al., 2000). Dependendo das características do estresse e da planta, haverá uma resposta de resistência ou suscetibilidade a ele, resultando na morte do organismo ou em sua sobrevivência e crescimento (Bray et al., 2000). Entretanto, ainda é pouco explorado como uma planta percebe alterações ambientais e como ela desencadeia sinais ativadores das respostas fisiológicas (Hung et al., 2005).

\subsubsection{Estresse e desenvolvimento vegetal}

Sob condições de estresse, uma das estratégias adotadas pelas plantas é 
desacelerar o crescimento, conservando energia para defesa e limitando o risco de danos (Vranová et al., 2002). Dessa forma, o estresse pode aumentar a tolerância da planta ao próprio fator estressante durante respostas de indução e aclimatação, sendo que essa tolerância se relaciona a uma série de respostas morfológicas, fisiológicas e bioquímicas que diminuem a exposição ao estresse, limitam o dano ou facilitam o reparo de sistemas danificados (Potters et al., 2007).

Se o estresse for suportável, ele intensifica o metabolismo e induz mecanismos adaptativos, que incluem a reprogramação da expressão gênica e alterações na fisiologia e no metabolismo celular, gerando uma homeostase na nova condição (Féher et al., 2003). No entanto, a capacidade das plantas de neutralizar as condições de estresse depende da eficiência e da velocidade com que elas reconhecem o estresse, geram moléculas sinalizadoras e ativam mecanismos de proteção (Pasternak et al., 2005). Sabendo-se que as plantas podem perceber o estresse, desencadeando eficientemente as respostas de defesa apropriadas, entretanto pouco se conhece sobre como essa informação é veiculada à maquinaria do ciclo celular (May et al., 1998).

Diferentes estresses abióticos induzem respostas morfogênicas que compreendem uma mistura de inibição e ativação do crescimento (Potters et al., 2007). Dentre os diferentes fatores abióticos que podem levar uma planta ao estresse, os metais pesados, a hipoxia, as deficiências nutricionais e a radiação UV-B têm sido reconhecidos como indutores de respostas morfogênicas, enquanto que alterações no metabolismo de auxina e espécies reativas de oxigênio (ROS) são consideradas sinalizadores dessas respostas induzidas por estresse (SIMR) (Potters et al., 2007).

\subsubsection{Cultivo in vitro, organogênese e estresse}

O cultivo in vitro de células e tecidos vegetais fornece um modelo benéfico 
para a investigação dos eventos morfológicos, bioquímicos e moleculares que ocorrem no início do desenvolvimento das plantas (Kanmegne \& Omokolo, 2003). No entanto, a técnica pode expor as plantas a fatores considerados estressantes, tais como: remoção do ambiente original do tecido, perturbação mecânica, composição do meio de cultura (reguladores de crescimento, sais, compostos orgânicos), acúmulo de gases (especialmente o etileno), umidade aumentada, corrente transpiratória diminuída, alta ou baixa luminosidade e variação de temperatura.

A organogênese de tecidos cultivados in vitro resulta da influência das condições intrínsecas do desenvolvimento e de fatores ambientais, incluindo componentes do meio. A cultura de tecido in vitro leva a alterações no ambiente celular, expondo os explantes a estresses significativos, sendo um deles a injúria causada pela explantação, que é considerada um dos sinais envolvidos com a indução da desdiferenciação (Féher et al., 2003).

Acredita-se que a resistência da planta aos efeitos do estresse seja determinada pelo nível de atividades das enzimas antioxidantes e a capacidade de aumentar rapidamente essas atividades (Polesskaya et al., 2004). Além disso, alterações nas concentrações de aminoácidos têm sido associadas ao estado metabólico, o qual controla vários processos de crescimento de maneira homeostática. A prolina, por exemplo, foi considerada uma fonte de nitrogênio orgânico com papel protetor contra o estresse associado ao cultivo in vitro. Ela apresentou efeito promotor no processo de regeneração e embriogênese somática de Vigna mungo (L.) (Sen et al., 2002).

Pasternak et al. (2002) mostraram que o estresse oxidativo induzido pela adição de ferro ao meio de cultura aumentou a quantidade de auxinas endógenas e promoveu a divisão em protoplastos de folhas de alfafa (resultando em uma linhagem embriogênica), além de aumentar a atividade da peroxidase do ascorbato (um seqüestrador de peróxido de hidrogênio) no primeiro dia de cultivo. Esses autores 
sugerem que o aumento de auxinas e a sinalização do estresse podem ser eventoschave na adaptação celular, reprogramando o padrão de expressão gênica, metabolismo e fisiologia celular, resultando na totipotência e competência à formação de embriões somáticos.

\subsection{Estresse oxidativo}

O estresse oxidativo é descrito como um desbalanço entre espécies reativas de oxigênio (ROS) e antioxidantes nos sistemas biológicos. Pode ser desencadeado pela formação aumentada de ROS e/ou pela redução nas defesas antioxidantes, sendo que uma variedade de condições estressantes, tanto bióticas quanto abióticas, desencadeia um aumento de ROS em células animais e vegetais (Mahalingam \& Fedoroff, 2003). O estado redox é um determinante crítico da função celular e grandes desbalanços nesse estado podem causar danos severos à planta ou levá-la à morte (Dietz \& Scheibe, 2004).

\subsubsection{Espécies reativas de oxigênio (ROS)}

As plantas, como qualquer outro organismo aeróbico, requerem oxigênio para a produção eficiente de energia. Se a redução do $\mathrm{O}_{2}$ a $\mathrm{H}_{2} \mathrm{O}$ for parcial, podem ser formadas ROS, como radicais superóxido, peróxido de hidrogênio e radicais hidroxila, além de espécies reativas de enxofre e nitrogênio, particularmente o óxido nítrico e hidroperóxidos de lipídio (Vranová et al., 2002; Mahalingam \& Fedoroff, 2003). As ROS são altamente reativas com lipídeos de membrana, proteína e DNA; acredita-se que elas sejam os fatores que mais contribuem para as injúrias decorrentes do estresse e causem rapidamente danos celulares (Hung et al., 2005). 
As fontes enzimáticas de ROS estão localizadas tanto extra quanto intracelularmente, sendo que as mais importantes são as peroxidases e amino-oxidases (localizadas nas paredes celulares), NADPH-oxidases da membrana plasmática, oxidases e peroxidases da mitocôndria, cloroplastos, peroxissomos e núcleo (Mahalingam \& Fedoroff, 2003). Dado o fato de que as enzimas produtoras de ROS estão localizadas em diferentes compartimentos celulares, suas ativações dependem da natureza do estímulo desencadeador e da rota pela qual ele é percebido (Mahalingam \& Fedoroff, 2003).

A produção endógena de ROS é uma característica geral do estresse vegetal, visto que sua produção aumentada é observada em resposta a uma variedade de agentes estressantes abióticos, incluindo temperaturas extremas, alta luminosidade, déficit hídrico, herbicidas, entre outros (Mahalingam \& Fedoroff, 2003). As ROS não são unicamente moléculas sinalizadoras de estresse, mas podem também ser um sinal intrínseco do crescimento e desenvolvimento vegetal (Vranová et al., 2002). Altas concentrações de ROS podem levar à fitotoxicidade, enquanto concentrações relativamente baixas podem ser utilizadas para sinalização de aclimatação, o que confere extrema importância à modulação dos conteúdos de ROS nas plantas (Dat et al., 2000).

\subsubsection{ROS e desenvolvimento vegetal}

Alguns trabalhos sugerem uma ligação entre ROS e a fisiologia do desenvolvimento, embora a relação entre ROS e a diferenciação e regeneração de plantas ainda não seja bem compreendida.

A formação de radical hidroxila foi detectada durante respostas morfogênicas em hipocótilo de diferentes genótipos de linho (Linum usitatissimum L.) cultivados in vitro, com ou sem a adição de reguladores de crescimento (Obert et al., 
2005). O monitoramento da reatividade do radical hidroxila pôde dar uma indicação do potencial que os radicais livres têm para mediar o estresse em tecidos cultivados in vitro.

A diferenciação de células embriogênicas foi afetada positivamente por alta quantidade de $\mathrm{H}_{2} \mathrm{O}_{2}$ intracelular, o qual induziu e promoveu a embriogênese somática de Lycium barbarum (Kairong et al., 1999). Tian et al. (2003) investigaram a liberação de radicais peróxidos, peróxido de hidrogênio e a atividade de enzimas antioxidantes durante a organogênese. Os resultados dessa pesquisa sugerem que o peróxido de hidrogênio esteja correlacionado com o processo morfogenético em calos de morango, podendo atuar como mensageiro no processo de formação de primórdios de gemas.

\subsubsection{Peróxido de hidrogênio}

O peróxido de hidrogênio $\left(\mathrm{H}_{2} \mathrm{O}_{2}\right)$ é uma forma de ROS gerada no estresse oxidativo, moderadamente reativa, formada nos peroxissomos como parte da via fotorespiratória (Neill et al., 2002; Vranová et al., 2002). Quando formado pela oxidação de aminas, pode ser diretamente utilizado por peroxidases ligadas à parede na lignificação e fortalecimento da parede celular, tanto durante o crescimento normal quanto em resposta a estímulos externos. Além disso, desempenha possivelmente uma função na sinalização de respostas de defesa, não só contra patógenos, mas também na sinalização de estresses abióticos como ferimentos, alterações térmicas ou excesso de luz (Vranová et al., 2002). Alguns outros processos biológicos que também utilizam a sinalização do $\mathrm{H}_{2} \mathrm{O}_{2}$ são: a morte celular programada, o fechamento estomático e o gravitropismo de raiz regulado por auxina (Neill, Desikan \& Hancock, 2002).

Kairong et al. (1999) afirmam que, embora o $\mathrm{H}_{2} \mathrm{O}_{2}$ seja um agente oxidante fraco entre as ROS, o fato de ele poder ser gerado em uma grande variedade de 
tipos celulares e de ser capaz de penetrar membranas celulares rapidamente faz com que tenha o mais importante papel em funções celulares. Hung et al. (2005) sugerem que entre as ROS, $0 \mathrm{H}_{2} \mathrm{O}_{2}$ parece ser o mais adequado para desempenhar o papel de molécula sinalizadora, devido à sua alta estabilidade e longa meia-vida. Ainda segundo esses autores, $\mathrm{O}_{2} \mathrm{O}_{2}$ agiria como um sinal de estresse, ao mesmo tempo em que a flutuação do seu conteúdo endógeno nas plantas refletiria alterações espaciais e temporais do meio ambiente.

$\mathrm{O} \mathrm{H}_{2} \mathrm{O}_{2}$ modula a expressão de vários genes, incluindo aqueles que codificam enzimas antioxidantes e moduladores da sua produção, indicando a maneira complexa pela qual as concentrações endógenas de $\mathrm{H}_{2} \mathrm{O}_{2}$ podem ser monitoradas e mantidas em nível constante. (Neill et al., 2002). A enzima catalase e o ciclo ascorbatoglutationa são importantes vias no seqüestro de $\mathrm{H}_{2} \mathrm{O}_{2}$ e, embora suas propriedades sejam diferentes, funcionam efetivamente em paralelo (Dat et al., 2000).

\subsection{Antioxidantes}

As plantas têm um sistema de defesa bem desenvolvido contra as ROS, tanto limitando sua formação quanto instituindo sua remoção (Alscher et al., 2002). Esse sistema constitui uma complexa gama de antioxidantes enzimáticos e não enzimáticos que regulam as ROS, protegendo as células dos danos oxidativos (Vranová et al., 2002). Enzimas, incluindo catalase (CAT), superóxido dismutase (SOD), peroxidase (POX), ascorbato peroxidase $(A P X)$ e glutationa redutase $(G R)$ e os antioxidantes nãoenzimáticos como tocoferóis, ácido ascórbico e glutationa trabalham em conjunto para regular as quantidades de ROS (Hung et al., 2005).

O grau de estresse oxidativo em uma célula pode ser determinado pelas quantidades de radicais superóxido, hidroxila e peróxido de hidrogênio (Apel \& Hirt, 
2004). Portanto, o balanço das atividades de SOD, APX e CAT é essencial para suprimir quantidades tóxicas de ROS em uma célula.

\subsubsection{Ascorbato}

O ácido ascórbico, também conhecido como ascorbato, desempenha um papel essencial na sobrevivência dos organismos vegetais. É um agente antioxidante que, em associação com outros componentes do sistema antioxidante, protege as plantas contra danos oxidativos resultantes dos metabolismos aeróbico, fotossintético e da poluição (Smirnoff, 1996). Ele está presente no citossol, cloroplasto, vacúolo, mitocôndria e matriz extracelular (Potters et al., 2002).

O ascorbato pode ser encontrado na forma reduzida (ASC), semi-oxidada (monodehidroascorbato - MDHA) e totalmente oxidada (dehidroascorbato - DHA) (Potters et al., 2002). A oxidação do ASC resulta inicialmente na formação do radical MDHA, o qual pode ser convertido em ASC ou DHA, sendo este último instável em pH acima de 7 , portanto é necessário manter o pool de ascorbato total na forma reduzida para evitar perdas rápidas (Smirnoff, 1996). A ciclagem eficiente entre as formas oxidadas e reduzidas do ASC minimiza a degradação do DHA e diminui a necessidade por altas taxas de síntese de novo (Horemans et al., 2000). O esquema representativo da ciclagem do ascorbato, conhecido por ciclo ascorbato-glutationa, está representado na figura 1.

Uma maneira pela qual as plantas sintetizam o ASC envolve intermediários da produção de L-galactono-y-lactona (GAL), precursora imediata do ASC (Horemans et al., 2000). Esse processo de biossíntese parece ocorrer na membrana mitocondrial interna. Segundo Smirnoff (1996), essa via é apoiada pela rápida conversão da GAL exógena a ASC e pela caracterização de uma enzima mitocondrial (GAL desidrogenase) que catalisa a oxidação de GAL a ASC. 


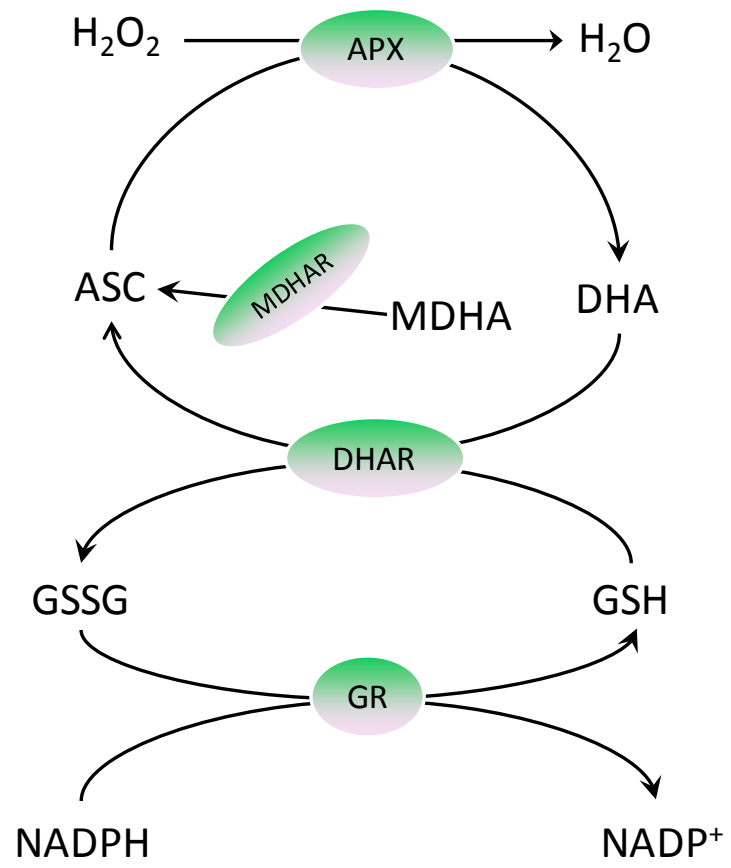

Figura 1 - Esquema representativo do ciclo ascorbato-glutationa (modificado de Inzé \& Van Montagu, 1995). $\mathrm{H}_{2} \mathrm{O}_{2}$ : peróxido de hidrogênio; APX: ascorbato peroxidase; ASC: ascorbato; MDHA: monodehidroascorbato; MDHAR: monodehidroascorbato redutase; DHA dehidroascorbato; DHAR: dehidroascorbato redutase; GSH: glutationa; GSSG: glutationa dissulfídeo; GR: glutationa redutase.

Entre as funções biológicas do ASC descritas em plantas, podem ser citadas as propriedades antioxidantes e as induções da divisão e do alongamento celular (Horemans et al., 2000). Como antioxidante, sugere-se que o ascorbato seja o principal composto para a eliminação de ROS, especialmente o $\mathrm{H}_{2} \mathrm{O}_{2}$ (Hung et al., 2005). A enzima APX catalisa a redução do $\mathrm{H}_{2} \mathrm{O}_{2}$ em água e tem alta especificidade e afinidade pelo ascorbato como agente redutor (Smirnoff, 2000). Há evidências sugerindo uma dupla ação do ASC no crescimento celular: primeiro, modificando o ciclo celular e estimulando células quiescentes à divisão; e segundo, acelerando a expansão e o alongamento celular (Horemans et al., 2000). O ascorbato é capaz de influenciar o progresso do ciclo celular em plantas, sendo o DHA a forma redox ativa nesse processo (Potters et al., 2000). 


\subsubsection{Glutationa}

A glutationa, um tripeptídeo de glutamato, cisteína e glicina ( $\vee$-Glu-CysGly), é um metabólito multifuncional nas plantas, ao mesmo tempo em que é um grande "reservatório" de enxofre reduzido não-protéico (Noctor et al., 2002). É um agente antioxidante, que participa do controle da homeostase celular, ajudando a evitar o estresse oxidativo. Ela ocorre nos tecidos animais e vegetais sob duas formas redox: a forma reduzida, glutationa (GSH) e a forma oxidada (GSSG) (Potters et al., 2002).

A biossíntese e o papel da glutationa no metabolismo vegetal têm sido discutidos há vários anos (May et al., 1998; Noctor et al., 1998, 2002). A via de biossíntese é bem estabelecida e similar entre plantas, animais e microrganismos. As plantas sintetizam glutationa a partir de carbono inorgânico, nitrogênio e enxofre, empregando os aminoácidos glutamato, cisteína e glicina (Noctor \& Foyer, 1998). Para formar o tripeptídeo completo, os aminoácidos constituintes são unidos em dois passos dependentes de ATP; o primeiro deles, catalisado pela enzima Y-glutamilcisteína sintetase ( $\mathrm{Y}$-ECS), forma $\mathrm{Y}$-glutamilcisteína e o segundo, catalisado pela glutationa sintetase (GSH-S), produz GSH por meio da adição de um resíduo de glicina (Noctor et al., 2002; Cobbett et al., 1998).

Alguns estudos com animais têm demonstrado uma influência positiva da glutamina sobre a reversão dos efeitos do metabolismo oxidativo. Babu et al. (2001) observaram que a glutamina reverteu os efeitos do metabolismo oxidativo em fígado de ratos neonatos e que a efetividade desse aminoácido parece ter sido mediada via síntese de glutationa. Yu et al. (1999) observaram em tecido hepático de ratos que a glutamina seria um precursor vital do glutamato para a síntese de glutationa. De acordo com esses autores, o glutamato é pouco transportado para dentro das células e parte da molécula desse aminoácido é derivada da glutamina. Ao contrário, a glutamina seria eficientemente transportada através da membrana celular, sendo desaminada na mitocôndria para 
produzir glutamato e $\mathrm{NH}_{3}$. O glutamato seria então transportado de volta ao citossol, ficando disponível para a síntese de glutationa. Portanto, a glutamina atuaria como precursor vital do glutamato para a síntese de glutationa.

Outros autores afirmam que a síntese de glutationa é controlada primariamente pela atividade da y-ECS e disponibilidade de cisteína (Noctor et al., 2002; Anderson, 1998). Ao contrário da cisteína, há poucos dados que indiquem haver uma limitação da síntese de glutationa pela disponibilidade de glutamato e, pelo menos em folhas iluminadas e sob condições não estressantes, a concentração de glicina seria suficientemente alta para suportar taxas máximas de síntese de glutationa (Noctor et al., 1998).

A biossíntese de GSH parece ser uma resposta intrínseca das plantas ao estresse, sendo estimulada quando as células se encontram sob condições estressantes, aumentando sua capacidade de defesa (May et al., 1998; Potters et al., 2002). Geralmente, o papel fisiológico da glutationa nas células vegetais envolve, além da defesa contra o estresse oxidativo, o metabolismo do enxofre e a desintoxicação de compostos xenobióticos (Potters et al., 2002).

A $\mathrm{GSH}$ reage quimicamente com ROS, mas a redução do $\mathrm{H}_{2} \mathrm{O}_{2}$ dependente de GSH não é a principal rota de destruição dessa espécie reativa do oxigênio, já que a reação entre esses dois compostos é lenta (Noctor et al., 1998, 2002). Em plantas, o maior substrato para a desintoxicação redutiva do $\mathrm{H}_{2} \mathrm{O}_{2}$ é o ascorbato, que deve ser continuamente regenerado a partir de suas formas oxidadas. A principal função da glutationa na proteção contra o estresse oxidativo é a redução do ascorbato oxidado no ciclo ascorbato-glutationa (Noctor et al., 1998) (Fig. 1).

A flutuação do conteúdo de GSH também poderia ser utilizada como um bom indicador do estado redox nas células vegetais (Hung et al., 2005). A avaliação do 
estado redox da planta é importante, porque a alteração desse estado apontaria se a planta está submetida ou não a uma condição estressante (Munné-Bosch et al. 2004). O balanço GSH/GSSG parece ser mais influente no controle da expressão gênica e atividade protéica que a quantidade absoluta de glutationa, sendo que a proporção de glutationa na forma reduzida (GSH) reflete as taxas relativas de redução e oxidação, sendo sempre maiores que 0,9 sob condições não estressantes (Noctor et al., 1998, 2002).

\subsubsection{Superóxido Dismutase}

A enzima superóxido dismutase (SOD) seqüestra o radical superóxido $\left(\mathrm{O}_{2}{ }^{-}\right)$ (Mizuno et al., 1998). Dentro de uma célula, essa enzima constitui a primeira linha de defesa contra as ROS sendo, portanto, crucial que essa enzima esteja presente para a remoção do $\mathrm{O}_{2}$ 'nos compartimentos onde ele é formado (Alscher et al., 2002).

Segundo Mizuno et al. (1998), muitas plantas possuem um número de isoformas da SOD que estão localizadas em diversos compartimentos celulares. Dependendo do co-fator utilizado pela enzima, as SODs são classificadas em três grupos: FeSOD (cloroplastos); MnSOD (mitocôndrias e peroxissomos); e Cu/ZnSOD (cloroplastos, citossol e possivelmente no espaço extracelular) (Bowler et al., 1992; Alscher et al., 2002).

De acordo com Konieczny et al. (2008), as diferentes isoformas da SOD são as principais seqüestradoras de $\mathrm{O}_{2}{ }^{-}$, enquanto a remoção do excesso de $\mathrm{H}_{2} \mathrm{O}_{2}$ da célula é realizada por catalases e peroxidases.

Já foram estudadas diferenças na atividade das enzimas antioxidantes durante a organogênese e embriogênese somática em várias espécies vegetais cultivadas in vitro (Cui et al., 1999; Gupta \& Datta, 2003; Tang \& Newton, 2005; 
Konieczny et al., 2008).

A SOD reage com radicais superóxido para produzir $\mathrm{H}_{2} \mathrm{O}_{2}$. Como a ação da SOD resulta na formação de $\mathrm{H}_{2} \mathrm{O}_{2}$, essa enzima está intimamente ligada ao ciclo ascorbato-glutationa. Assim, a SOD age em paralelo com outras enzimas e antioxidantes conferindo uma regulação altamente otimizada que reduz a formação de radical hidroxila. A discussão da SOD, portanto, precisa considerar o sistema de defesa do estresse oxidativo como um todo (Bowler et al., 1992).

\subsubsection{Catalase}

Em plantas, a enzima catalase (CAT) é encontrada predominantemente nos peroxissomos, onde atua principalmente na remoção do $\mathrm{H}_{2} \mathrm{O}_{2}$ formado durante a fotorespiração (Bowler et al. 1992). Essa enzima apresenta baixa ou nenhuma atividade no citossol, na mitocôndria e nos cloroplastos (Mizuno et al., 1998).

Apesar da sua localização restrita, a CAT pode ter um papel significativo na defesa contra o estresse oxidativo, removendo o $\mathrm{H}_{2} \mathrm{O}_{2}$ de outros compartimentos subcelulares que não os peroxissomos, pois $\mathrm{O}_{2} \mathrm{H}_{2}$ pode facilmente se difundir pelas membranas (Bowler et al. 1992; Willekens et al., 1997).

A CAT não utiliza poder redutor para sua atividade e possui uma alta taxa de reação e menor afinidade pelo $\mathrm{H}_{2} \mathrm{O}_{2}$ do que a enzima ascorbato peroxidase (APX) (Inzé \& Van Montagu, 1995; Willekens et al., 1970). A APX necessita de ascorbato como poder redutor e possui uma maior afinidade pelo $\mathrm{H}_{2} \mathrm{O}_{2}$, permitindo o seqüestro de pequenas quantidades dessa ROS em locais mais específicos (Willekens et al., 1997). Segundo Mittler (2002), a diferença de afinidade da APX e da CAT pelo $\mathrm{H}_{2} \mathrm{O}_{2}$ sugere que elas pertençam a duas classes distintas de enzimas seqüestradoras de ROS: a APX deve ser responsável pela modulação fina de ROS para a sinalização, enquanto a CAT deve 
ser responsável pela remoção do excesso de ROS durante o estresse.

\subsection{Abacaxizeiro e Organogênese}

O cultivo in vitro tem sido utilizado para aquisição de conhecimento fisiológico de bromélias como, por exemplo, necessidades nutricionais, produção endógena de hormônios e outros aspectos do desenvolvimento desse grupo de plantas (Mercier \& Kerbauy, 1997).

Em abacaxizeiro (Ananas comosus), folhas cultivadas in vitro representam um modelo de organogênese onde não há a formação prévia de um calo: o desenvolvimento de um eixo caulinar adventício é precedido pela formação, na base da folha, de um aglomerado celular chamado de protuberância (Mercier et al., 2003). Essas protuberâncias diferem dos calos por apresentarem um sistema vascular organizado (Carneiro, 1997).

Os estudos sobre organogênese a partir de explantes foliares de abacaxizeiro têm investigado aspectos relacionados a esse evento morfogenético, como: condições de cultivo para obtenção de novas plantas (Sripaoraya et al., 2003); conteúdos endógenos de auxinas e citocininas associados à formação de eixos caulinares adventícios (Mercier et al., 2003); o envolvimento da glutamina e conteúdo hormonal endógeno no aumento da competência organogenética (Hamasaki et al., 2005); quantificação de aminoácidos endógenos durante a indução da organogênese adventícia (Kitakawa, 2004).

O cultivo in vitro das bases foliares de abacaxizeiro pode constituir per se uma condição estressante aos explantes, a qual pode estar relacionada com o processo de organogênese adventícia. Entretanto, essa relação estresse versus organogênese ainda não foi estudada no modelo citado, sendo o que se propõe este trabalho. 


\section{OBJETIVOS}

O presente trabalho teve como principal objetivo compreender o papel da glutamina no favorecimento da organogênese adventícia em bases foliares de abacaxizeiro cultivado in vitro. Especificamente, procurou-se verificar se a glutamina estaria envolvida com uma possível diminuição do estresse oxidativo durante o período de indução da organogênese.

Para tanto, buscou-se correlacionar a influência do suprimento do meio de cultura com glutamina aos teores endógenos de peróxido de hidrogênio, glutationa, ascorbato e com o estado redox da glutationa e do ascorbato endógenos ao longo do processo de organogênese de gemas caulinares adventícias surgidas nas bases foliares de abacaxizeiro cultivado in vitro. Além disso, foram analisadas as atividades de duas enzimas antioxidantes nesses explantes foliares, a superóxido dismutase e a catalase. Tentativamente, a glutationa foi adicionada ao meio de cultura, contendo ou não glutamina, visando conhecer o efeito desse antioxidante no processo organogenético. 


\section{CONCLUSÕES E PERSPECTIVAS}

No presente trabalho foram verificados alguns aspectos da organogênese adventícia em bases foliares de abacaxizeiro, relacionando-os a um possível estresse oxidativo, que ocorreria nos explantes em virtude do cultivo in vitro, e a ações da glutamina em diminuir esse estresse.

Com os resultados aqui apresentados, foi possível chegar às seguintes conclusões a respeito do evento morfogenético estudado:

1) a glutationa pareceu ser capaz de substituir a glutamina no seu efeito sobre a organogênese das bases foliares de abacaxizeiro, mas não de intensificar essa resposta. Além disso, esse antioxidante não substituiu o efeito positivo da glutamina em relação ao ganho de massas fresca e seca dos eixos caulinares de abacaxizeiro formados. No entanto, atuou favoravelmente na formação de um maior número de gemas adventícias por explante.

2) a cultura in vitro das bases foliares pareceu causar uma condição estressante para os explantes logo no início do período de cultivo, fato esse indicado pela alta concentração de $\mathrm{H}_{2} \mathrm{O}_{2}$ detectada nas primeiras 24 horas em relação aos demais tempos. No entanto, esse possível estresse oxidativo pode ser controlado ao longo do período de cultivo. A glutamina pareceu favorecer a manutenção de um estado redox reduzido tanto de ASC quanto de GSH no período em que houve esse possível estresse oxidativo sugerindo, talvez, que o aumento na concentração de $\mathrm{H}_{2} \mathrm{O}_{2}$ no $1^{\circ}$ dia tenha participado da sinalização da organogênese nos explantes SIMGIn.

3) os resultados das atividades das enzimas antioxidantes sugerem que a CAT pode ter sido responsável pela regulação do conteúdo endógeno de $\mathrm{H}_{2} \mathrm{O}_{2}$, já que a SOD não apresentou alterações expressivas ao longo do período de indução da organogênese tanto em SIM quanto em SIMGIn.

Em resumo, o cultivo in vitro das bases foliares de abacaxizeiro pareceu 
ter gerado um estresse oxidativo nesses tecidos. Entretanto, esses explantes pareceram responder rapidamente a esse estresse, retornando a uma homeostase e conferindo condição para que as células seguissem a um programa de rediferenciação e determinação à organogênese caulinar. Por outro lado, essa situação de estresse pode ter sido justamente o sinal de que os explantes precisam para que a organogênese se inicie. A glutamina teria, então, um papel de manter o estado redox dos tecidos foliares reduzido no momento da maior concentração de $\mathrm{H}_{2} \mathrm{O}_{2}$ endógeno.

Como perspectivas, para que se possa ter uma visão mais completa de como o estresse oxidativo interfere no processo da organogênese em abacaxizeiro, seriam necessários estudos que procurassem analisar o comportamento de outras enzimas envolvidas no metabolismo antioxidante, como o da GR, o da APX e de outras peroxidases. Também seria interessante investigar como a suplementação do meio de cultura com peróxido de hidrogênio, antes e depois do isolamento dos explantes, interferiria na taxa de organogênese adventícia. Outra abordagem seria a investigação das relações dos componentes do estresse oxidativo com os teores de hormônios vegetais envolvidos em tal processo organogenético. 


\section{RESUMO}

Diversos estudos têm demonstrado o envolvimento benéfico da utilização do aminoácido glutamina em meios de cultura, favorecendo a organogênese dos tecidos vegetais cultivados. Sabe-se que as fontes de nitrogênio podem influenciar na produção endógena de fitormônios, entretanto o papel exato da glutamina ainda não está bem estabelecido. Em Ananas comosus (L.) Merr., a adição de glutamina ao meio de cultura exerceu efeito promotor sobre a taxa de organogênese e o vigor do crescimento das gemas caulinares a partir de bases foliares. Além da glutamina, discute-se se o estresse resultante da explantação também poderia estar envolvido com a indução do processo organogenético, acarretando na produção de espécies reativas de oxigênio e na alteração do estado redox endógeno. Esse estresse para ser benéfico, entretanto, deveria estar restrito a certo limite.

O presente trabalho visou compreender o efeito favorável da glutamina na organogênese adventícia em bases foliares de abacaxizeiro cultivadas in vitro. envolvimento da glutamina com uma possível diminuição do estresse oxidativo durante o período de indução da organogênese também foi abordado. Para tanto, buscou-se correlacionar a influência do suprimento de glutamina no meio de cultura com os teores endógenos de peróxido de hidrogênio, glutationa e ascorbato. O estado redox da glutationa e do ascorbato durante o período de indução da organogênese adventícia também foi analisado. Além disso, foram analisadas as atividades de duas enzimas antioxidantes nesses explantes foliares, a superóxido dismutase e a catalase. Tentativamente, a glutationa foi adicionada ao meio de cultura, contendo ou não glutamina, visando conhecer o efeito desse antioxidante no processo organogenético.

Os resultados mostraram que a glutationa substituiu, mas não intensificou, o efeito benéfico da glutamina sobre a taxa de organogênese das bases foliares de 
abacaxizeiro. Esse antioxidante não substituiu o efeito positivo do aminoácido no ganho de massas fresca e seca dos eixos caulinares formados, no entanto atuou favoravelmente na formação de um maior número de gemas adventícias por explante inoculado. Ao que parece, o cultivo in vitro das bases foliares gerou um estresse oxidativo nesses tecidos logo no início do período de cultivo, a julgar pela alta concentração de $\mathrm{H}_{2} \mathrm{O}_{2}$ detectada nas primeiras 24 horas. Entretanto, essa possível condição estressante foi controlada ao longo do período de cultivo, retornando a uma homeostase do tecido e conferindo condição para que as células se reprogramassem para seguir a uma rota de organogênese caulinar. A glutamina pareceu favorecer a manutenção de um estado redox reduzido tanto de ASC quanto de GSH durante o período em que houve o possível estresse oxidativo. Os resultados das atividades das enzimas antioxidantes sugeriram que a CAT pode ter sido responsável pela regulação do conteúdo endógeno de $\mathrm{H}_{2} \mathrm{O}_{2}$, já que a SOD não apresentou alterações expressivas ao longo do período de indução da organogênese tanto em SIM quanto em SIMGIn. Em conjunto, os resultados sugerem que o estresse oxidativo causado pelo cultivo in vitro pode ter gerado uma sinalização importante para que a organogênese se inicie, sendo que a glutamina exerceria um papel de manter o estado redox dos tecidos foliares reduzido no momento da maior concentração de $\mathrm{H}_{2} \mathrm{O}_{2}$ endógeno. 


\begin{abstract}
A positive influence of glutamine on organogenesis of in vitro cultured plant tissues has been demonstrated by several studies. It is well known that the endogenous synthesis of phytohormones can be influenced by nitrogen sources, although it is not completely established in which way glutamine acts in this process. The addition of this amino acid to the culture medium has enhanced the organogenesis rate and resulted in a better vigor of the shoots that were originated from the leaf bases of Ananas comosus (L.) Merr. cultured in in vitro conditions. It is also suggested that the tissue excision may result in a stressful condition by increasing the production of reactive oxygen species and changing the endogenous redox state, which might be involved in the induction of organogenic process. However, this stress should be beneficial only if restricted.
\end{abstract}

The aim of this work was to comprehend the positive influence of glutamine on the in vitro adventitious organogenesis of pineapple leaf bases. It was also attempted to determine whether the glutamine would be involved on a possible oxidative stress decrease during the organogenesis induction. In order to answer these questions, we tried to correlate the presence of glutamine in the culture medium and the endogenous hydrogen peroxide, glutathione, ascorbate levels. The redox state of these antioxidants is also analyzed during the induction of adventitious shoot organogenesis. Moreover, two antioxidants enzymes activities are quantified in the leaf explants: catalase and superoxide dismutase. The glutathione influence on the process was also investigated, considering the glutamine presence or not. It was done in order to establish the effect of this antioxidant in the organogenic process.

The results showed that glutathione could replace, but not enhance, the positive effect of glutamine on the organogenesis rate of pineapple leaf bases. This antioxidant did not substitute the positive effect presented by the glutamine on the 
acquisition of fresh and dry masses by the new shoots. On the other hand, glutathione enhanced the number of adventitious buds per explant. Apparently, the excision of the leaf bases and its subsequent cultivation in the induction culture medium resulted in the tissue oxidative stress early in the first 24 hours of incubation. This could be inferred by the high $\mathrm{H}_{2} \mathrm{O}_{2}$ concentrations detected during this period. However, this possible stressful condition was controlled during the culture period, leading to the return of the homeostasis of the tissue and allowing the cells to become determined to shoot organogenesis. During the probable period of oxidative stress, glutamine seemed to maintain the reduced redox state on both ASC and GSH. The results of the antioxidant enzymes activities suggested that CAT may have been responsible for the regulation of the endogenous $\mathrm{H}_{2} \mathrm{O}_{2}$ levels, while SOD did not showed significant changes during the induction of organogenesis of leaf bases cultivated either in SIM or SIMGIn. Taken together, the results obtained in this work suggest that the oxidative stress caused by the excision of the leaf tissues and its in vitro cultivation may be an important signal to the induction of the leaf organogenesis. Furthermore, the glutamine may have a role in the maintenance of the reduced redox state when higher levels of endogenous $\mathrm{H}_{2} \mathrm{O}_{2}$ are present in the tissues. 


\section{REFERÊNCIAS BIBLIOGRÁFICAS}

AEBI, H. (1984). Catalase in vitro. Methods in Enzymology, v. 105, p. 121-130.

ALSCHER, R.G.; ERTURK, N. \& HEATH, L.S. (2002). Role of superoxide dismutase (SODs) in controlling oxidative stress in plants. Journal of Experimental Botany, v. 53, p. 1331-1341.

ANDERSON, M.E. (1998). Glutathione: an overview of biosynthesis and modulation. Chemico-Biological Interactions, v. 111-112, p. 1-14.

APEL, K. \& HIRT, H. (2004). Reactive oxygen species: metabolism, oxidative stress, and signal transduction. Annual Review in Plant Biology, v. 53, p. 373-399.

BABU, R. et al. (2001). Glutamine and glutathione counteract the inhibitory effects of mediators of sepsis in neonatal hepatocytes. Journal of Pediatric Surgery, v. 36, p. 282286.

BEAUCHAMP, C. \& FRIDOVICH, I. (1971). Superoxide dismutase: Improved assays and an assay applicable to acrylamide gels. Analytical Biochemistry, V. 44, p. 276-287.

BOWLER, C.; Van MONTAGU, M. \& INZÉ, D. (1992). Superoxide dismutase and stress tolerance. Annual Review of Plant Molecular Biology, v. 43, p. 83-116.

BRADFORD, M. M. (1976). A rapid and sensitive method for the quantitation of microgram quantities of protein utilizing the principle of protein-dye binding. Analytical Biochemistry, v. 72, p. 248-254.

BRAY, E.A.; BAIEY-SERRES, J. \& WERETILNYK, E. Responses to abiotic stresses. In: Buchanan, B.; Gruissem, W. \& Jones, R. (eds.). Biochemistry \& Molecular Biology of Plants. Rockville: American Society of Plant Physiologists, 2000, p. 1158-1203.

CARNEIRO, L.A. (1997). Controle da morfogênese in vitro de três espécies de bromélias do sudeste brasileiro. Tese (Doutorado). 87p. ESALQ-USP. Piracicaba.

CHRISTIANSON, M.L. \& WARNICK, D.A. (1985). Temporal requirement for phytohormone balance in the control of organogenesis in vitro. Developmental Biology, v. 112, p. 494-497.

COBBETT, C.S. et al. (1998). The glutathione-deficient, cadmium-sensitive mutant, cad21 , of Arabidopsis thaliana is deficient in $\mathrm{Y}$-glutamylcysteine synthetase. The Plant Journal, v. 16, p. 73-78.

CORUZZI, G. \& LAST, R. Amino acids. In: Buchanan, B.; Gruissem, W. \& Jones, R. (eds.). Biochemistry \& Molecular Biology o f Plants. Rockville: American Society of Plant Physiologists, 2000, p. 358-410.

CUI, K. et al. (1999). Effect of hydrogen peroxide on somatic embryogenesis of Lycium barbarum L. Plant Science, v.146, p.9-16.

DAT, J. et al. (2000). Dual action of the active oxygen species during plant stress responses. Cellular and Molecular Life Science, v. 57, p. 779-795. 
DIETZ, K-J. \& SCHEIBE, R. (2004). Redox regulation: an introduction. Physiologia Plantarum, v.120, p.1-3.

DLUZNIEWSKA, P. et. al. (2006). Exogenous supply of glutamine and active cytokinin to the roots reduces $\mathrm{NO}_{3}$ uptake rates in poplar. Plant Cell Environment, v. 29, p. 12841297.

DOMÍNGUEZ-VALDIVIA, M.D. et al. (2008). Nitrogen nutrition and antioxidant metabolism in ammonium-tolerant and -sensitive plants. Physiologia Plantarum, v. 132, p. 359-369.

FEHÉR, A.; PASTERNAK, T.P. \& DUDITS, D. (2003). Transition of somatic plant cells to an embryogenic state. Plant Cell, Tissue and Organ Culture, v. 74, p. 201-228.

FOYER, C.H. \& NOCTOR, G. (2005). Oxidant and antioxidant signalling in plants: a reevaluation of the concept of oxidative stress in a physiological context. Plant, Cell and Environment, v. 28, p. 1056-1071.

FRANKLIN, C.I. \& DIXON, R.A. Initiation and maintenance of callus and cell suspension cultures. In: Dixon, R.A. \& Gonzales, R.A. (eds.) Plant Cell Culture - A pratical approach. Oxford: Oxford University Press, 1994, p. 1-25.

GAMBORG, O.L. (1970). The effects of amino acids and ammonium on the growth of plant cells in suspension culture. Plant Physiology, v. 45, p. 372-375.

GASPAR, T. et al. (2002). Concepts in plant stress physiology. Application to plant tissue cultures. Plant Growth Regulation, v. 37, p. 263-285.

GREEN, P.B. (1980). Organogenesis - a biophysical view. Annual Review of Plant Physiology, v. 31, p. 51-82.

GUPTA, S.D. \& DATTA, S. (2003). Antioxidant enzyme activities during in vitro morphogenesis of gladiolus and the effect of application of antioxidants on plant regeneration. Biologia Plantarum, v. 47, p. 179-183.

HAMASAKI, R.M. (2003). Indução da organogênese adventícia em tecido foliar de Ananas comosus (L.) Merr. (Bromeliaceae) cultivado in vitro: importância da glutamina e de fitormônios. Dissertação (Mestrado). 96 p., IB-USP, São Paulo.

HAMASAKI, R.M.; PURGATTO, E. \& MERCIER, H. (2005). Glutamine enhances competence for organogenesis in pineapple leaves cultivated in vitro. Brazilian Journal of Plant Physiology, v. 17, p. 273-281.

HICKS, G.S. (1994). Shoot induction and organogenesis in vitro: a developmental perspective. In Vitro Cellular and Developmental Biology: Plant, v. 30, p. 10-15.

HOREMANS, N. et al. (2000). Ascorbate function and associated transport systems in plants. Plant Physiology and Biochemistry, v. 38, p. 531-540.

HUNG, S-H.; YU, C-W \& LIN, C.H. (2005) Hydrogen peroxide functions as a stress signal in plants. Botanical Bulletin of Academia Sinica, v.46, p. 1-10.

INZÉ, D. \& Van MONTAGU, M. (1995). Oxidative stress in plants. Current Opinion in Biotechnology, v. 6, p. 153-158. 
JOY IV, R.W.; BENDER, L. \& THORPE, T.A. (1994). Nitrogen metabolism in cultured cotyledon explants of Pinus radiate during de novo organogenesis. Physiologia Plantarum, v. 92, p. 681-688.

KAIRONG, C. et al. (1999). Effect of hydrogen peroxide on somatic embryogenesis of Lycium barbarum L. Plant Science, v.146, p.9-16.

KAMADA, H. \& HARADA, H. (1979). Influence of several growth regulators and amino acids on in vitro organogenesis of Torenia fournieri Lind. Journal of Experimental Botany, v. 30, p. 27-36.

(1984). Changes in endogenous amino acid composition during somatic embryogenesis in Daucus carota L. Plant and Cell Physiology, v. 25, p. 27-38.

KANMEGNE, G. \& OMOKOLO, N.D. (2003). Changes in phenol content and peroxidase activity during in vitro organogenesis in Xanthosoma sagittifolium L. Plant Growth Regulation, v. 40, p. 53-57.

KERSTETTER, R.A. \& HAKE, S. (1997). Shoot meristem formation in vegetative development. The Plant Cell, v. 9, p. 1001-1010.

KITAKAWA, A.Y. (2004). Quantificação de aminoácidos livres endógenos durante a indução da organogênese adventícia em bases foliares de abacaxizeiro. Dissertação (Mestrado). 90 p., IB-USP, São Paulo.

KNUDSON, I. (1946). A new nutrient solution for germination of orchid seed. American Orchid Society Bulletin, v. 15, p. 214-217.

KONIECZNY, R. et al. (2008). Oxidative events during in vitro regeneration of sunflower. Acta Physiologiae Plantarum, v. 30, p. 71-79.

LARCHER, W. Physiological Plant Ecology. Springer Verlag, New York, 1980.

LEA, P.J. Nitrogen metabolism. In: Lea, P.J. \& Leegood, R.C. (eds.) Plant Biochemistry and Molecular Biology. John Wiley \& Sons Ltd., 1993, p. 155-180.

MAHALINGAM, R. \& FEDOROFF, N. (2003). Stress response, cell death and signaling: the many faces of reactive oxygen species. Physiologia Plantarum, v.119, p.56-68.

MAY, M.J. et al. (1998). Glutathione homeostasis in plants: implications for environmental sensing and plant development. Journal of Experimental Botany, v.49, p.649-667.

McCORD, J.M., FRIDOVICH, I. (1969). Superoxide dismutase, an enzymic function for erythrocuprein (hemocuprein). The Journal of Biological Chemistry, v. 244, p. 60496055.

MEDICI, L.O. et al. (2004). The influence of nitrogen supply on antioxidant enzymes in plant roots. Functional Plant Biology, v. 31, p. 1-9.

MERCIER, H. \& KERBAUY, G.B. Micropropagation of Ornamental Bromeliads (Bromeliaceae). In: Bajaj, Y.P.S. (ed.), Biotechnology in Agriculture and Forestry. High Tech and Micropropagation VI. Heidelberg: Springer - Verlag, 1997, v. 40, p. 43-57 
(1998). Endogenous IAA and cytokinin levels in bromeliad shoots as influenced by glutamine and ammonium nitrate treatments. Revista Brasileira de Fisiologia Vegetal, v. 10, p. 225-228.

MERCIER, $\mathrm{H}$. et al. (1997). Effects of $\mathrm{NO}_{3}, \mathrm{NH}_{4}{ }^{+}$and ureia nutrition on endogenous levels of IAA and four cytokinins in two epiphytic bromeliads. Plant, Cell and Environment., v. 20, p. 387-392.

MERCIER, H. et al. (2003). Endogenous auxin and cytokinin contents associated with shoot formation in leaves of pineapple cultured in vitro. Brazilian Journal of Plant Physiology, v. 15, p. 107-112.

MITTLER, R. (2002). Oxidative stress, antioxidants and stress tolerance. Trends in Plant Science, v. 7 p. 405-410.

MILAZZO, M.C. et al. (1998). Regulation of benzyladenine-induced in vitro shoot organogenesis and endogenous proline in melon (Cucumis melo L.) by exogenous proline, ornithine, and proline analogues. Journal of Agricultural and Food Chemistry, v.46, p.2402-2406.

MITTLER, R. (2002). Oxidative stress, antioxidants and stress tolerance. Trends in Plant Science, v. 7, p. 405-410.

MITTLER, R.; VANDERAUWERA, S.; GOLLERY, M. \& Van BREUSEGEM, F. (2004). Reactive oxygen gene network of plants. Trends in Plant Science, v. 9, p. 490-498.

MIZUNO, M.; KAMEI, M. \& TSUCHIDA, H. (1998). Ascorbate peroxidase and catalase cooperate for protection against hydrogen peroxide generated in potato tubers during lowtemperature storage. IUBMB Life, v. 44, p. 717-726.

MUNNÉ-BOSCH, S. et al. (2004). Airbone ethylene may alter antioxidant protection and reduce tolerance of holm oak to heat and drought stress. Plant Physiology, v.136, p.2937-2947.

MURASHIGE, T. \& SKOOG, F. (1962). A revised medium for rapid growth and bioassays with tobacco tissue cultures. Physiologia Plantarum, v.15, p. 473-497.

NEILL, S.; DESIKAN, R. \& HANCOCK, J. (2002).Hydrogen peroxide signalling. Current Opinion in Plant Biology, v. 5, p. 388-395.

NEILL, S.J. et al. (2002). Hydrogen peroxide and nitric oxide as signalling molecules in plants. Journal of Experimental Botany, v.53, p.1237-1247.

NIKIFOROVA, V.J. et al. (2006). Effect of sulfur availability on the integrity of amino acid biosynthesis in plants. Amino Acids, v. 30, p. 173-183.

NILSEN, E. \& ORCUTT, D.M. The Physiology of Plants Under Stress - Abiotic factors. John Wiley and Sons, Inc., New York, 1996.

NOCTOR, G. et al. (1998). Glutathione: biosynthesis, metabolism and relationship to stress tolerance explored in transformed plants. Journal of Experimental Botany, v.49, p.623-647. 
NOCTOR, G. \& FOYER, C.H. (1998). Simultaneous measurement of foliar glutathione, $Y$ glutamylcysteyne, and amino acids by high-performance liquid chromatography: comparison with two other assay methods for glutathione. Analytical Biochemistry, v. 264, p.98-110.

NOCTOR, G. et al. (2002). Interactions between biosynthesis, compartmentation and transport in the control of glutathione homeostasis and signalling. Journal of Experimental Botany, v.53, p.1283-1304.

OBERT, B. et al. (2005). Moderation on morphogenetic and oxidative stress responses in flax in vitro cultures by hydroxynonenal and desferrioxamine. Journal of Plant Physiology, v. 162, p. 537-547.

OGITA, S. et al. (2001). The effects of glutamine on the maintenance of embryogenic cultures of Cryptomeria japonica. In Vitro Cellular and Developmental Biology: Plant, v. 37 , p. $268-273$.

PASTERNAK, T.P. et al. (2002). The role of auxin, $\mathrm{pH}$, and stress in the activation of embryogenic cell division in leaf protoplast-derived cells of alfalfa. Plant Physiology, $v$. 129 , p. 1807-1819.

PASTERNAK, T.P. et al. (2005). Complementary interactions between oxidative stress and auxins control plant growth responses at plant, organ and cellular level. Journal of Experimental Botany, v.56, p.1991-2001.

POLESSKAYA, O.G.; KASHIRINA, E.I. \& ALEKHINA, N.D. (2004) Changes in the activity of antioxidant enzymes in wheat leaves and roots as a function of nitrogen source and supply. Russian Journal of Plant Physiology, v. 51, p. 615-620.

POTTERS, G. (2002). The role of ascorbate in the regulation of cell cycle and cellular redox status in a Nicotiana tabacum L. cv. Bright Yellow-2 cell culture. Tese (Doutorado). 164 p., Departement Biologie, Faculteit Wetenschappen, Universiteit Antwerpen (Antuérpia, Bélgica).

POTTERS,G. et al. (2000). Ascorbate and dehydroascorbate influence cell cycle progression in tobaco cell suspension. Plant Physiology, v.124, p. 17-20.

POTTERS, G. et al. (2002). Ascorbate and glutathione: guardians of the cell cycle, partners in crime? Plant Physiology and Biochemistry, v.40, p.537-548.

POTTERS, G. et al. (2007). Stress-induced morphogenic responses: growing out of trouble? Trends in Plant Science, v. 12, p. 98-105.

RAO, K.V. et al. (2005). Induction of multiple shoots from leaf segments, in vitro-flowering and fruiting of a dwarf tomato (Lycopersicon esculentum). Journal of Plant Physiology, v. 162 , p. 959-962.

SEN, J; KALIA, S. \& GUHA-MUKERJEE, S. (2002). Level of endogenous free amino acids during various stages of culture of Vigna mungo (L.) Hepper - somatic embryogenesis, organogenesis and plant regeneration. Current Science, v. 82, p. 429433.

SHETTY, K.; ASANO, Y. \& OOSAWA, K. (1992). Stimulation of in vitro shoot organogenesis in Glycine $\max$ (Merrill.) by allantoin and amides). Plant Science, v. 81, p. 245-251. 
SMIRNOFF, N. (1996). The function and metabolism of ascorbic acid in plants. Annals of Botany, v.78, p.661-669.

SMIRNOFF, N. (2000). Ascorbic acid: metabolism and fuctions of a multi-facetted molecule. Current Opinion in Plant Biology, v. 3, p. 229-235.

SOUZA, B.M. et al. (2003). Relationships between endogenous hormonal levels and axillary bud development of Ananas comosus nodal segments. Plant Physiology and Biochemistry, v. 41, p. 733-739.

SRIPAORAYA, S. et al. (2003). Plant regeneration by somatic embryogenesis and organogenesis in commercial pineapple (Ananas comosus L.). In Vitro Cellular and Developmental Biology: Plant, v. 39, p. 450-454.

SUGIYAMA, M. (1999). Organogenesis in vitro. Current Opinion in Plant Biology, v. 2, p. 61-64.

TANG, W. \& GUO, Z. (2001). In vitro propagation of loblolly pine via direct somatic organogenesis from mature cotyledons and hypocotyls. Plant Growth Regulation, v. 33, p. 25-31.

TANG, W. \& NEWTON, R.J. (2005) Peroxidase and catalase activities are involved in direct adventitious shoot formation induced by thidiazuron in eastern white pine (Pinus strobes L.) zygotic embryos. Plant Physiology and Biochemistry, v. 43, p. 760-769.

TANIMOTO, S. \& HARADA, H. (1989). Involvement of the accumulation of glutamine in the initiation of adventitious buds in stem segments of Torenia. Plant and Cell Physiology, v. 30, p. 541-547.

TEWARI, R.K.; KUMAR, P. \& SHARMA, P.N. (2007). Oxidative stress and antioxidant responses in young leaves of mulberry plants grown under nitrogen, phosphorus or potassium deficiency. Journal of Integrative Plant Biology, v. 49, p. 313-322.

TIAN, M.; GU, Q. \& ZHU, M. (2003). The involvement of hydrogen peroxide and antioxidant enzymes in the process of shoot organogenesis of strawberry callus. Plant Science, v.165, p.701-707.

TSAI, C-J. \& SAUNDERS, J.W. (1999). Evaluation of sole nitrogen sources for shoot and leaf disc cultures of sugarbeet. Plant Cell, Tissue and Organ Culture, v. 59, p. 47-56.

VALDÉS, A.E. et al. (2001). Relationships between hormonal contents and the organogenic response in Pinus pinea cotyledons. Plant Physiology and Biochemistry, v. 39 , p. 377-384.

Van GESTELEN et al. (1998). The cantharidin-induced oxidative burst in tobacco BY-2 cell suspension cultures. Protoplasma, v. 205, p. 83-92.

VASUDEVAN, A. et al. (2004). Glutamine: a suitable nitrogen source for enhanced shoot multiplication in Cucumis sativus L. Biologia Plantarum, v. 48, p. 125-128.

VRANOVÁ, E.; INZÉ, D. \& VAN BREUSEGEM, F. (2002). Signal transduction during oxidatibe stress. Journal of Experimental Botany, v. 53, p.1227-1236. 
WEIGEL, D. \& DEAN, C. (2002). Development, evolution and adaptation. Current Opinion in Plant Biology, v.5, p. 11-13.

WILLEKENS, H. et al. (1997). Catalase is a sink for $\mathrm{H} 2 \mathrm{O} 2$ and is indispensable for stress defence in C3 plants. The EMBO Journal, v.16, p. 4806-4816.

YU Jian-Chun, JIANG Zhu-Ming \& LI De-Min (1999). Glutamine: a precursor of glutathione and its effects on liver. World Journal of Gastroenterology, v.5, p.143-146. 